\title{
Habilidades Sociais e Problemas de Comportamento de Pré- Escolares: Comparando Avaliações de Mães e de Professoras
}

\author{
Preschooler's Social Skills and Behavior Problems: Comparison between \\ Mother and Teacher Assessments
}

\author{
Alessandra Turini Bolsoni-Silva ${ }^{\mathrm{a} *}$, Edna Maria Marturano ${ }^{\mathrm{b}}$, \\ Verônica Aparecida Pereira ${ }^{a}$, Jair Wagner de Souza Manfrinato ${ }^{a}$, \\ ${ }^{a}$ Universidade Estadual Paulista Júlio de Mesquita Filho, Bauru, Brasil, ${ }^{b}$ Universidade de São Paulo, Ribeirão Preto, Brasil
}

\begin{abstract}
Resumo
Este estudo comparou avaliações de mães e professoras, sobre habilidades sociais e problemas de comportamento de crianças, identificadas pelas professoras, como tendo problemas de comportamento. Participaram mães e professoras de 24 crianças com problemas de comportamento e 24 crianças indicadas como sendo socialmente habilidosas. Foram utilizados o Questionário de Comportamentos Socialmente Adequados e a Escala Comportamental Infantil, versões para pais e professores. Os principais resultados foram: (a) mães e professoras de crianças sem problemas não diferiram na avaliação das habilidades sociais, mas diferiram quanto aos problemas, percebidos em nível mais alto pelas mães; (b) mães e professoras de crianças com problemas diferiram na avaliação dos problemas de comportamento e das habilidades sociais; as mães perceberam mais habilidades e menos problemas; (c) diferenças de gênero foram encontradas apenas para problemas de comportamento das crianças com problemas. Os resultados indicam a necessidade de ter diferentes informantes, em diferentes contextos, na avaliação do comportamento de crianças.

Palavras-chave: Problemas de comportamento; habilidades sociais; avaliação por mães e professoras.
\end{abstract}

\begin{abstract}
This work compared assessments carried out by mothers and teachers about the social skills and behavior problems of children identified by their teachers as having behavior problems. Participants were mothers and teachers of 24 preschool children presenting behavior problems, and 24 preschool children with high levels of social skills. The instruments used were the Socially Desired Behavior Questionnaire and the Rutter Child Behavior Scale: versions for parents and teachers. The main results were: (a) mothers and teachers of children without behavior problems scored similar social skills, but different behavior problems, in which mothers perceived more behavior problems than teachers; (b) mothers and teachers of children presenting behavior problems scored both social skills and behavior problems differently, in which mothers perceived higher levels of social skills and less behavior problems; (c) gender differences were found only for behavior problems of the children presenting behavior problems. Results point to the need to have different informants, in different settings, in the assessment of child behavior.

Keywords: Behavior problems; social skills; assessment by mothers and teachers.
\end{abstract}

Pais e professores, como observadores privilegiados do comportamento das crianças, têm sido auxiliares importantes dos psicólogos, tanto na pesquisa como na prática profissional. Este artigo trata de avaliações comportamentais feitas por mães e professoras. Seu foco são habilidades sociais e problemas de comportamento de pré-escolares.

Segundo Del Prette e Del Prette (2005), o termo habilidades sociais "aplica-se às diferentes classes de comportamentos sociais do repertório de um indivíduo, que contribuem para a competência social, favorecendo um relacionamento saudável e produtivo com as demais pessoas"

\footnotetext{
* Endereço para correspondência: Av. Eng. Luiz Edmundo C. Coube, s/n., Vargem Limpa , Bauru, SP, 17.015-970. E-mail: bolsoni@fc.unesp.br / veronica@fc.unesp.br / jwsouzafeb@unesp.br / emmartur@fmrp.usp.br

Este trabalho é parte de um trabalho maior que culminou em Tese de Doutorado da primeira autora, sob a orientação da segunda autora, cujo título é "Habilidades Sociais Educativas, variáveis contextuais e problemas de comportamento: comparando pais e mães de pré-escolares", defendida na FFCL da USP-RP.
}

(p. 31). Habilidades sociais promovem o desenvolvimento e previnem o surgimento de problemas de comportamento à medida que possibilitam que as crianças interajam mais positivamente com colegas, professores e familiares, aumentando a chance de acesso a reforçamento social, como elogios e atenção. Nesta linha de raciocínio, tais comportamentos poderiam ser considerados como "saltos" comportamentais (Rosales-Ruiz \& Baer, 1997), os quais dizem respeito a mudanças no processo de desenvolvimento que seriam importantes ou para o indivíduo ou para a espécie, pois permitiriam que a criança entrasse em contato com contingências relevantes para a aprendizagem, seja social, seja acadêmica.

Essa previsão derivada do conceito de "saltos" comportamentais tem sido confirmada pela literatura: na fase pré-escolar, crianças com maior competência interpessoal, segundo a avaliação dos professores, apresentam menos problemas de comportamento, maior 
envolvimento ativo nas atividades de aprendizagem em sala de aula e melhor desempenho acadêmico, tanto atual como em anos subseqüentes (Coolahan, Fantuzzo, Mendez \& McDermott, 2000; Coplan, Gavinski-Molina, LagacéSéguin \& Wichmann, 2001).

A mesma lógica, utilizada para caracterizar habilidades sociais por referência a "saltos" comportamentais, pode ser aplicada para definir problemas de comportamento. Estes seriam excessos ou déficits comportamentais que dificultariam o acesso da criança a novas contingências relevantes de aprendizagem, promotoras do desenvolvimento.

Comportamentos internalizantes e externalizantes são categorias amplas de problemas de comportamento, identificadas através de pesquisas, que podem ser associadas aos conceitos de excesso e déficit comportamental (Hinshaw, 1992; Pacheco, Alvarenga, Repppold, Piccinini \& Hutz, 2005). Comportamentos internalizantes são evidenciados por retraimento, depressão, ansiedade e queixas somáticas. Em contraposição, comportamentos externalizantes $^{1}$ são marcados por impulsividade, agressão, agitação, características desafiantes e anti-sociais. Ambos dificultam os "saltos" comportamentais do desenvolvimento, já que os internalizantes podem privar a criança de interagir com o ambiente, isto é, o indivíduo pode evitar iniciar uma interação com pares ou adultos e, por outro lado, os externalizantes podem gerar conflitos e provocar rejeição de pais, professores e colegas (Coplan, Findlay \& Nelson, 2004; Patterson, Reid \& Dishion, 2002).

Essa divisão básica, nos dois tipos amplos de comportamentos, pode ser identificada precocemente, já em crianças de 3 a 6 anos (LaFreniere \& Dumas, 1996). Na fase préescolar, comportamentos externalizantes são mais freqüentes e diminuem com a idade (Graminha, 1994a), podendo ser considerados como características transitórias do desenvolvimento normal. Entretanto, dependendo de sua intensidade e do modo como o ambiente lida com essas manifestações, elas representam risco ao desenvolvimento, sendo preditoras de dificuldades precoces nos relacionamentos com os colegas (Keane \& Calkins, 2004) e posterior problema de comportamento (Webster-Stratton, 1996).

Investigações sobre o repertório de habilidades sociais e problemas de comportamento de crianças são baseadas freqüentemente no relato de mães e professores. Essa ênfase justifica-se, dado que a família e a escola são os principais contextos de desenvolvimento, onde pais e professores são observadores privilegiados do comportamento da criança.

Quando se compara o julgamento das mães com o dos professores, duas tendências são observadas. A primeira é que a concordância entre avaliações é significativa, porém modesta em magnitude; essa tendência se verifica, seja em relação aos comportamentos considerados facilitadores do desenvolvimento, seja em relação aos comportamentos considerados problemáticos (Achenbach, McConaughy \&

1 Uma noção mais abrangente do conceito, incluindo padrões de sentimentos e pensamentos, tem sido defendida nos anos recentes; essa noção é comentada por Szelbracikowski e Dessen (2005)
Howell, 1987; Kumpulainen et al., 1999; Ruffallo \& Elliott, 1997). A segunda é que as mães são mais severas, fazendo avaliações menos favoráveis (Gagnon, Vitaro \& Tremblay, 1992; Satake, Yoshida, Yamashita, Kinukawa \& Takagishi, 2003; Touliatos \& Lindholm, 1981).

Diversas interpretações têm sido apresentadas para essas tendências. Em relação à correlação modesta entre os julgamentos, a interpretação imediata de que uma ou ambas as fontes de informação são inválidas ou não confiáveis tem sido rejeitada em favor da hipótese de especificidade situacional, que considera que desacordos entre informantes poderiam refletir variações no funcionamento da criança em diferentes contextos e com diferentes parceiros de interação (Achenbach et al., 1987). Estudos recentes compartilham dessa interpretação, considerando que mães e professoras mantêm relacionamentos diferentes com a criança e a observam em condições diferentes. Além disso, as mães provavelmente têm mais oportunidades para observar seus filhos e as expectativas sobre o comportamento podem diferir, notadamente quando mãe e professora pertencem a grupos sociais diversos (Feitosa, 2003; Gagnon et al., 1992; Satake et al., 2003).

O julgamento mais desfavorável das mães tem sido alvo de menor atenção que a baixa concordância entre mães e professores. Em seu estudo com crianças japonesas, Satake et al. (2003) especulam que as mães podem ser menos tolerantes por terem investido mais em seus filhos, ou que elas têm expectativas mais altas talvez por terem menos informação sobre o desenvolvimento infantil. Uma explicação alternativa seria que a percepção mais negativa da mãe tem uma base na realidade, tanto quanto a da professora, apenas refletindo o fato de que as crianças tendem a se expressar mais livremente em casa e de modo mais contido na escola, dado que diferentes tipos de contingências operam nos dois contextos. Em um espaço público, tal como o da escola, as regras de convivência impõem restrições a comportamentos que muitas vezes são tolerados no espaço privado do lar.

Estudos que compararam crianças com diferentes níveis de competência social apóiam essa segunda interpretação. Feitosa (2003), por exemplo, investigando a avaliação de pais (maioria mães) e professores sobre habilidades sociais de escolares com e sem dificuldades de aprendizagem, verificou que os pais fazem avaliações menos favoráveis apenas em relação às crianças sem dificuldade; em comparação com os professores, eles avaliam mais positivamente o comportamento das crianças com dificuldade.

Pesquisas sobre regulação das emoções mostram que crianças de $3-4$ anos já são capazes de controlar a expressão de emoções negativas frente à frustração em situações sociais não familiares; todavia, essa capacidade está prejudicada nas crianças que são indicadas tanto pelas mães, como pelas professoras, como tendo problemas de comportamento em nível clínico (Cole, Zahn-Waxler \& Smith, 1994; LaFreniere \& Dumas, 1996).

Esses achados sobre controle expressivo em pré-escolares, além de oferecerem evidência indireta da capacidade 
precoce das crianças para discriminar entre ambientes mais ou menos permissivos, possibilitam avançar na compreensão dos resultados aparentemente contraditórios sobre a maior severidade das mães, em relação às professoras, quando se trata de avaliar o comportamento de seus filhos. Dado que as crianças pré-escolares diferem em sua capacidade de inibir emoções negativas em situações menos familiares e considerando que a escola é um contexto menos familiar que o lar, algumas suposições podem ser feitas: (a) crianças socialmente competentes mostram menos comportamentos problemáticos e mais comportamentos socialmente adequados na escola que em casa; (b) crianças com problemas de comportamento apresentam comportamentos problemáticos indiscriminadamente, tanto em casa como na escola. Considerando ainda que o ambiente escolar, por mais complexo, coloca maiores exigências para as crianças, pode-se supor que as crianças com problemas de comportamento teriam maiores dificuldades para exibir, no contex to escolar, os comportamentos socialmente competentes que elas já exibem em casa, segundo avaliação verbal das mães.

A presente pesquisa considera essas duas possibilidades, focalizando tanto problemas de comportamento como comportamentos socialmente habilidosos. Seu objetivo principal é comparar avaliações de mães e professoras acerca de problemas de comportamento e habilidades sociais de préescolares, previamente indicados pelas professoras como tendo ou não problemas de comportamento na escola. A partir das suposições levantadas no parágrafo precedente, são feitas as seguintes previsões: (a) crianças sem problemas de comportamento na escola recebem avaliação mais negativa das mães que das professoras, em relação a problemas de comportamento; (b) crianças com problemas de comportamento na escola recebem avaliação mais positiva das mães que das professoras, em relação a suas habilidades sociais.

\section{Método}

\section{Participantes}

Participaram do estudo 48 mães e 22 professoras de crianças com idade entre cinco e sete anos, que moravam com ambos os pais biológicos, matriculadas em 13 Escolas Municipais de Educação Infantil (EMEIS), distribuídas geograficamente por uma cidade do interior de São Paulo. Metade da amostra é composta por 24 crianças indicadas pelas professoras como tendo problemas de comportamento na escola (Grupo IPC); a outra metade constitui-se de crianças indicadas pelas professoras como apresentando comportamentos socialmente habilidosos (Grupo ICSH).

No grupo IPC havia oito meninas e 16 meninos; a idade média das crianças indicadas era de 5 anos e 9 meses. No grupo ICSH, havia 17 meninas e sete meninos, com idade média de 5 anos e 11 meses. A distribuição por gênero apresentou diferença estatisticamente significativa entre os grupos $\left(\mathrm{X}_{2}=6,76 ; \mathrm{p}<0,01\right)$. Os grupos eram equivalentes quanto à escolaridade materna (IPC, média 9,35anos; ICSA, média 9,42 anos), à renda familiar (IPC, média $\mathrm{R} \$$ 870,00; ICSH, média R \$ 1.292,00), ao status ocupacional da mãe (em ambos os grupos havia 10 mães inseridas no mercado de trabalho) e à jornada de trabalho das mães que estavam empregadas (seis mães no Grupo IPC e sete no ICSH tinham jornada integral; as demais trabalhavam fora meio período).

\section{Instrumentos}

Para avaliação das habilidades sociais, foi utilizado o Questionário de Comportamentos Socialmente Habilidosos, em suas versões para professores (QCSH-Professores) e pais (QCSH-Pais), ambas baseados em Bolsoni-Silva (2000). Para avaliar os problemas de comportamento, foi empregada a Escala Comportamental Infantil (ECI), também com versões para professores (Rutter, 1967; Santos, 2002) e pais (Graminha, 1994b; 1998).

A ECI-B para Professores e a ECI-A2 para Pais são compostas, respectivamente, por 26 e 36 itens que apresentam descrições de comportamentos (por exemplo, "briga frequentemente com outras crianças"). Cada item tem três alternativas de resposta: o comportamento descrito se aplica (escore 2), aplica-se em parte (escore 1) ou não se aplica (escore 0 ) à criança. Ambas as escalas têm pontos de corte, acima dos quais se considera que a criança tem problemas de comportamento (escore igual ou superior a 16, na ECI-A; igual ou superior a 9, na ECI-B). A ECI-A tem adaptação brasileira, feita em uma amostra de 1731 crianças de 3 a 13 anos, com índices satisfatórios de fidedignidade e determinação de ponto de corte (Graminha, 1994a, 1994b, 1998). A ECI-B foi traduzida por Santos (2002), que verificou que o ponto de corte original da escala discriminava crianças com alto e baixo rendimento escolar.

O QCSH-Pais e o QCSH-Professores são compostos por uma lista (a versão para pais tem 19 itens e a versão para professores tem 24 itens) com comportamentos socialmente habilidosos apresentados por crianças, no qual os professores e os pais devem responder se um comportamento se aplica (escore 2), se aplica em parte (escore 1) ou não se aplica (escore 0). Os escores são somados, permitindo o escore total da criança avaliada.

\section{Procedimentos}

Para compor a amostra foram visitadas 13 EMEIS, após a permissão concedida pela Secretaria Municipal de Educação Infantil. Em seguida, foi solicitada à direção das EMEIS permissão para que suas professoras participassem da pesquisa. A cada professora, após a assinatura do Termo de Consentimento Livre e Esclarecido, solicitou-se que indicasse, entre seus alunos, os três que apresentavam mais problemas de comportamento e os três com maiores indicativos de comportamentos socialmente habilidosos. As professoras responderam, para cada criança indicada, à Escala Comportamental Infantil B (ECI-B) e também ao Questionário de Comportamentos Socialmente Habilidosos para Professores (QCSH-Professores).

Para inclusão no Grupo IPC, a criança indicada deveria atingir a pontuação da ECI-B para problema de comportamento. Como se estabeleceu que deveria haver na amostra o mesmo número de crianças IPC e ICSH para cada professora, 
quando a criança indicada não atingia o critério, não apenas ela era excluída da amostra, mas também o era o seu par correspondente

Junto às mães, os passos de coleta de dados foram: (a) contato, por telefone ou pessoalmente, para verificar o interesse em participar da pesquisa e para agendar a aplicação dos instrumentos nas suas residências; (b) visitas às residências, onde foram explicitados novamente os objetivos do trabalho, solicitando-se o consentimento e assinatura do Termo de Consentimento Livre e Esclarecido; (c) aplicação dos questionários do QCSH-Pais e da ECI-A.

Para o tratamento dos dados, o primeiro passo foi selecionar os itens dos instrumentos que estavam presentes tanto na versão para professores como na versão para pais. Em seguida, os dados referentes às perguntas dos repertórios de habilidades sociais e indicativos de problemas de comportamento foram tratados estatisticamente em cada um de seus itens.

A análise dos dados focalizou os escores totais dos instrumentos e os escores dos itens. A análise dos itens se baseou em duas medidas, a saber, ocorrência e intensidade do comportamento. Para comparações entre os grupos IPC e ICSH, quanto à ocorrência dos comportamentos, foi empregado o Teste Exato de Fisher. Nas análises focalizando medidas de intensidade, o teste Wilcoxon foi usado para comparar avaliações de mães e professoras dentro de um mesmo grupo, enquanto o teste U de Mann-Whitney foi usado para comparações de gênero dentro de cada grupo - IPC e ICSH.

\section{Resultados}

Preliminarmente, foi verificado se a composição dos grupos, a partir da indicação das professoras, teria uma correspondência na avaliação das mães. Comparando-se os grupos através do Teste U, nos escores totais dos instrumentos a que as mães responderam, verificou-se diferença significativa na ECI ( $p<0,05)$, com o Grupo IPC recebendo escores mais altos de problemas de comportamento. Os grupos IPC e ICSH não diferiram na avaliação das mães sobre habilidades sociais.

Focalizando a ocorrência dos comportamentos, a Tabela 1 mostra o número de crianças que apresentam os comportamentos socialmente habilidosos avaliados pelo QCSH, segundo professoras e mães.

Diferenças estatísticas foram encontradas em 9 dos itens avaliados do ponto de vista das professoras, conforme a Tabela 1. Os comportamentos com maior ocorrência no Grupo ICSH são: "procura ajudar", "cumprimenta as pessoas", "faz elogios", "toma iniciativas”, "expressa desejos de forma apropriada”, "expressa carinho", "expressa direitos e necessidades de forma apropriada”, "expressa sentimentos de

Tabela 1

Habilidades Sociais: Número de Crianças que apresentam a Habilidade, segundo as Professoras e as Mães. Comparações com o Teste Exato de Fisher.

\begin{tabular}{|c|c|c|c|c|c|c|}
\hline \multirow{3}{*}{ Habilidades sociais } & \multicolumn{6}{|c|}{ Número de crianças indicadas por } \\
\hline & \multicolumn{3}{|c|}{ Professoras } & \multicolumn{3}{|c|}{ Mães } \\
\hline & IPC & ICSH & $\mathrm{p}^{*}$ & IPC & ICSH & $\mathrm{p}^{*}$ \\
\hline \multicolumn{7}{|l|}{ Disponibilidade sociale cooperação } \\
\hline Faz pedido & 18 & 19 & - & 23 & 24 & - \\
\hline Procura ajudar & 18 & 24 & 0,011 & 22 & 19 & - \\
\hline Procura sua atenção & 20 & 20 & - & 24 & 24 & - \\
\hline Faz perguntas & 20 & 20 & - & 24 & 24 & - \\
\hline Cumprimenta as pessoas & 14 & 23 & 0,002 & 21 & 24 & - \\
\hline Faz elogios & 13 & 20 & 0,030 & 22 & 24 & - \\
\hline Toma iniciativas & 15 & 22 & 0,018 & 22 & 21 & - \\
\hline \multicolumn{7}{|l|}{ Expressão de sentimentos e enfrentamento } \\
\hline Expressa desejos de forma apropriada & 17 & 23 & 0,024 & 24 & 23 & - \\
\hline Expressa carinho & 19 & 24 & 0,025 & 24 & 24 & - \\
\hline Expressa direitos e necessidades apropriadamente & 15 & 24 & 0,001 & 21 & 24 & - \\
\hline Expressa desagrado de forma apropriada & 12 & 22 & 0,002 & 24 & 23 & - \\
\hline Expressa opiniões & 20 & 23 & - & 22 & 24 & - \\
\hline Usualmente está de bom humor & 20 & 24 & - & 22 & 24 & - \\
\hline Negocia & 14 & 19 & - & 19 & 19 & - \\
\hline \multicolumn{7}{|l|}{ Interação social positiva } \\
\hline Comunica-se de forma positiva & 21 & 24 & - & 22 & 24 & - \\
\hline Faz amigos & 20 & 24 & - & 21 & 23 & - \\
\hline Brinca com colegas & 23 & 24 & - & 24 & 24 & - \\
\hline Interage - não verbal & 18 & 24 & 0,001 & 24 & 24 & - \\
\hline
\end{tabular}

Nota: $*$ Indicado apenas quando $\mathrm{p}=<0,05$. 
desagrado de forma apropriada", "interage de forma nãoverbal”. Não foram encontradas diferenças entre as avaliações das mães IPC e ICSH.

$\mathrm{Na}$ Tabela 2 encontra-se o número de crianças que apresentam problemas de comportamento avaliados pela ECI, segundo os relatos das professoras e das mães.

$\mathrm{Na}$ avaliação das professoras, conforme a Tabela 2, foram encontradas diferenças significativas em 14 dos 23 itens avaliados ("impaciente - irrequieto", "fica pouco tempo em atividade", "destrói objetos", "briga freqüentemente", "irritável”, "muitas vezes é desobediente", "maltrata outras crianças”, "não é querido por outras crianças", "fala mentiras", "mata ou "enforca" aula", "recusa-se a entrar na escola", "parece tristonho - angustiado", "gagueja” e "tem outra dificuldade de fala”). Todos estes itens foram mais freqüentemente apontados para o Grupo IPC quando comparados ao ICSH.

Por outro lado, apenas três itens foram avaliados diferentemente por mães IPC e mães ICSH ("fica pouco tempo em uma atividade", "não é querido por outras crianças" e "fica facilmente preocupado"), sendo os dois primeiros mais freqüentemente apontados para o Grupo IPC e o último com mais freqüência para as crianças ICSH.

A Tabela 3, na página seguinte, apresenta as médias, no Grupo IPC, dos escores totais nos instrumentos, assim como dos comportamentos específicos com diferenças significativas nas comparações entre mães e professoras.
Pela Tabela 3, verifica-se que mães e professoras diferem na avaliação global do repertório de comportamentos das crianças IPC, tendo as mães uma avaliação mais favorável, tanto em relação aos comportamentos socialmente habilidosos como aos problemas de comportamento.

Nove comportamentos socialmente habilidosos obtiveram médias mais altas na avaliação feita pelas mães: "faz amigos", "cumprimenta as pessoas", "expressa sentimentos de desagrado", "faz elogios", "expressa desejos e preferências", "expressa carinhos", "comunica-se de forma positiva", "expressa direitos e necessidades", "negocia”.

Em relação aos itens indicativos de problemas de comportamento, foram obtidas diferenças significativas em 12 dos 23 itens, a maior parte com médias maiores na avaliação das professoras em comparação às mães.

Os itens que as professoras avaliaram mais desfavoravelmente que as mães foram: "fica pouco tempo em atividade", "briga freqüentemente", "maltrata outras crianças", "não é querido por outras crianças", "mata ou "enforca" aula", "recusa-se a entrar na escola", "parece tristonho - angustiado", "tende a ser fechado - solitário", "fica facilmente preocupado" e "gagueja". Apenas dois comportamentos tiveram médias mais altas na avaliação das mães: "tem queixas de dores de cabeça" e "rói as unhas ou os dedos".

Tabela 2

Problemas de Comportamento: Número de Crianças que Apresentam o Comportamento em cada Grupo, segundo as Professoras e as Mães. Comparações com o Teste Exato de Fisher.

\begin{tabular}{|c|c|c|c|c|c|c|}
\hline \multirow{3}{*}{ Problemas de comportamento } & \multicolumn{6}{|c|}{ Número de crianças indicadas por } \\
\hline & \multicolumn{3}{|c|}{ Professoras } & \multicolumn{3}{|c|}{ Mães } \\
\hline & IPC & ICSH & p* & IPC & ICSH & $\mathrm{p}^{*}$ \\
\hline Impaciente, irrequieto & 20 & 4 & 0,000 & 15 & 9 & - \\
\hline Fica pouco tempo em uma atividade & 20 & 3 & 0,000 & 11 & 2 & 0,004 \\
\hline Destrói objetos & 16 & $\mathrm{O}$ & 0,000 & 14 & 8 & - \\
\hline Briga freqüentemente & 18 & 3 & 0,000 & 10 & 6 & - \\
\hline Irritável & 15 & 1 & 0,000 & 14 & 14 & - \\
\hline Muitas vezes é desobediente & 16 & 3 & 0,000 & 19 & 15 & - \\
\hline Maltrata as crianças & 11 & $\mathrm{O}$ & 0,000 & 4 & 1 & - \\
\hline Não é querido por outras crianças & 16 & 0 & 0,000 & 6 & $\mathrm{O}$ & 0,011 \\
\hline Muitas vezes fala mentiras & 7 & 1 & 0,024 & 8 & 8 & - \\
\hline Ele (a) costuma roubar & 3 & o & - & 2 & 1 & - \\
\hline Mata ou "enforca" aula & 9 & 1 & 0,005 & 1 & 3 & - \\
\hline Recusa-se a entrar na escola & 9 & 1 & 0,005 & 2 & 1 & - \\
\hline Parece tristonho, angustiado & 13 & 1 & 0,000 & 5 & 3 & - \\
\hline Tende a ser fechado - solitário & 15 & 13 & - & 3 & 6 & - \\
\hline Fica facilmente preocupado(a) & 16 & 15 & - & 6 & 14 & 0,020 \\
\hline Tem medo & 11 & 9 & - & 16 & 19 & - \\
\hline Tem queixas de dores de cabeça & 1 & $\mathrm{O}$ & - & 6 & 11 & - \\
\hline É uma criança difícil, exigente & 11 & 14 & - & 6 & 2 & - \\
\hline Chupa os dedos & 1 & $\mathrm{O}$ & - & 1 & 1 & - \\
\hline Rói as unhas ou os dedos & 1 & 1 & - & 9 & 4 & - \\
\hline Apresenta tiques ou movimentos repetitivos & 1 & 0 & - & 4 & 1 & - \\
\hline $\operatorname{Ele}(a)$ gagueja & 6 & 1 & 0,049 & 2 & $\mathrm{O}$ & - \\
\hline Há outra dificuldade de fala & 5 & $\mathrm{O}$ & 0,025 & 4 & 2 & - \\
\hline
\end{tabular}

Nota: $*$ Indicado apenas quando $\mathrm{p}=<0,05$. 
Bolsoni-Silva, A. T., Marturano, E. M., Pereira, V. A., Manfrinato, J. W. S. (2006). Habilidades Sociais e Problemas de Comportamento de Pré-Escolares: Comparando Avaliações de Mães e de Professoras.

Tabela 3

Médias dos Escores Totais e dos Itens com Diferença Significativa nas Comparações entre Mães e Professoras, no Grupo IPC (Teste Wilcoxon).

\begin{tabular}{|c|c|c|c|}
\hline \multirow{2}{*}{ Variáveis } & \multicolumn{2}{|c|}{ Médias } & \multirow[b]{2}{*}{$\mathrm{p}$} \\
\hline & Prof. IPC & Mãe IPC & \\
\hline \multicolumn{4}{|l|}{ Habilidades sociais } \\
\hline Cumprimenta as pessoas & 0,96 & 1,63 & 0,013 \\
\hline Faz elogios & 0,71 & 1,50 & 0,004 \\
\hline Expressa desejos ... & 1,13 & 1,79 & 0,001 \\
\hline Expressa carinho & 1,17 & 1,92 & 0,001 \\
\hline Expressa direitos e ... & 0,83 & 1,38 & 0,050 \\
\hline Expressa desagrado ... & 0,75 & 1,63 & 0,001 \\
\hline Negocia & 0,88 & 1,42 & 0,019 \\
\hline Comunica-se de forma positiva & 1,25 & 1,63 & 0,029 \\
\hline Faz amigos & 1,46 & 1,71 & 0,034 \\
\hline Escore total QCSA & 21,75 & 29,72 & 0,001 \\
\hline \multicolumn{4}{|l|}{ Problemas de comportamento } \\
\hline Fica pouco tempo em atividade & 1,46 & 0,75 & 0,010 \\
\hline Briga freqüentemente & 1,29 & 0,50 & 0,001 \\
\hline Maltrata outras crianças & 0,63 & 0,17 & 0,017 \\
\hline Não é querido por outras criança & 1,08 & 0,29 & 0,002 \\
\hline Mata ou "enforca" aula & 0,54 & 0,08 & 0,009 \\
\hline Recusa-se a entrar na escola & 0,67 & 0,13 & 0,009 \\
\hline Parece tristonho, angustiado & 0,75 & 0,21 & 0,007 \\
\hline Tende a ser fechado - solitário & 1,17 & 0,21 & 0,001 \\
\hline Fica facilmente preocupado(a) & 1,08 & 0,54 & 0,002 \\
\hline Tem queixas de dores de cabeça & 0,08 & 0,38 & 0,038 \\
\hline Rói as unhas ou os dedos & 0,08 & 0,54 & 0,041 \\
\hline Ele gagueja & 0,42 & 0,08 & 0,046 \\
\hline Escore total itens equivalentes ECI-A e ECI-B & 16,46 & 10,18 & 0,000 \\
\hline
\end{tabular}

Tabela 4

Médias dos Escores Totais e dos Itens com Diferença Significativa nas Comparações entre Mães e Professoras, no Grupo ICSH (Teste Wilcoxon).

\begin{tabular}{|c|c|c|c|}
\hline \multirow{2}{*}{ Variáveis } & \multicolumn{2}{|c|}{ Médias } & \multirow[b]{2}{*}{$\mathrm{p}$} \\
\hline & Prof. & Mãe & \\
\hline Habilidades sociais & $\mathrm{ICSH}$ & $\mathrm{ICSH}$ & \\
\hline Procura ajudar & 1,96 & 1,33 & 0,003 \\
\hline Procura sua atenção & 1,46 & 2,00 & 0,006 \\
\hline Usualmamente está de bom humor & 2,00 & 1,79 & 0,025 \\
\hline Faz amigos & 1,96 & 1,79 & 0,046 \\
\hline Escore total QCSA & 31,62 & 30,83 & 0,304 \\
\hline \multicolumn{4}{|l|}{ Problemas de comportamento } \\
\hline Destrói objetos & 0,00 & 0,42 & 0,008 \\
\hline Irritável & 0,04 & 0,75 & 0,001 \\
\hline Muitas vezes é desobediente & 0,13 & 0,67 & 0,002 \\
\hline Muitas vezes fala mentiras & 0,04 & 0,33 & 0,020 \\
\hline Tende a ser fechado - solitário & 0,96 & 0,29 & 0,013 \\
\hline Tem medo & 0,38 & 0,96 & 0,006 \\
\hline Tem queixas de dores de cabeça & 0,00 & 0,54 & 0,002 \\
\hline É uma criança difícil, exigente & 1,13 & 0,08 & 0,000 \\
\hline Escore total itens equivalentes ECI-A e ECI-B & 4,38 & 7,01 & 0,028 \\
\hline
\end{tabular}


A Tabela 4 apresenta as médias dos indicadores de habilidades sociais e problemas de comportamento, com diferenças significativas nas comparações entre mães e professoras, assim como dos escores totais nos instrumentos, no Grupo ICSH.

Ao serem comparados os escores totais dos instrumentos, observa-se, pela Tabela 4, que as mães apresentaram uma média maior na identificação dos problemas de comportamento, ao passo que não houve diferença entre as avaliações de mães e professoras quanto aos indicadores de habilidades sociais.

Diferenças significativas foram encontradas em quatro itens do QCSH. As professoras fazem avaliações mais favoráveis para "procura ajudar", "faz amigos" e "usualmente está de bom humor". O item "procura sua atenção" foi avaliado como mais freqüente pelas mães.

Quanto aos itens da ECI, mães e professoras diferem significativamente, sendo a avaliação das mães mais negativa nos itens: "destrói objetos", "irritável”, "muitas vezes é desobediente", "muitas vezes fala mentiras", "tem medo", "tem queixas de dores de cabeça”. Apenas os comportamentos "tende a ser fechado - solitário" e "é difícil - exigente" receberam maior pontuação por parte das professoras.

Nas comparações de gênero, não foram encontradas diferenças no Grupo ICSH. Os resultados referentes ao Grupo IPC são apresentados na Tabela 5 .

Conforme a Tabela 5, comparações de gênero dos comportamentos socialmente "desejados" no Grupo IPC, na avaliação das mães, apontam que as meninas "tomam mais iniciativas" e "expressam opiniões" mais freqüentemente do que os meninos; já do ponto de vista das professoras, são os meninos quem mais "procuram sua atenção".

Diferenças de gênero no Grupo IPC, quanto aos comportamentos indicativos de problema, foram encontradas tanto na avaliação das mães como na das professoras. Segundo o relato das mães, no Grupo IPC as meninas, mais freqüentemente do que os meninos, "recusam-se a entrar na escola", "são fechadas - solitárias" e "ficam facilmente preocupadas”. Já as professoras apontaram que os meninos são mais "impacientes - irrequietos", "destroem objetos", "brigam” mais freqüentemente, são mais "desobedientes”, "maltratam outras crianças" e "enforcam" aula”.

\section{Discussão}

Este estudo, realizado com pré-escolares, buscou um maior entendimento a respeito da concordância entre mães e professoras, na avaliação do comportamento de crianças. Especificamente, procurou-se esclarecer o achado, ainda sem uma interpretação consistente, de que as mães avaliam as crianças com maior severidade, atribuindo-lhes níveis mais altos de problemas de comportamento. Confirmando a primeira previsão feita na introdução, os resultados reiteraram a maior severidade das mães apenas em relação a crianças consideradas socialmente competentes por suas professoras. Esses resultados estão coerentes com pesquisas sobre controle da expressão emocional em pré-escolares (Cole et al., 1994; LaFreniere \& Dumas, 1996). Resultados semelhantes foram encontrados por Feitosa (2003), ao comparar avaliações de habilidades sociais de escolares com e sem dificuldade de aprendizagem, feitas por pais / mães e professoras.

Ao demonstrar que a maior negatividade das mães é um fenômeno dependente de condições que podem ser previstas com base em pesquisa empírica, a investigação contribui para o campo de conhecimento sobre avaliação do comportamento de crianças por diferentes informantes, em diferentes contextos.

O conjunto dos resultados fortalece a hipótese de especificidade situacional (Achenbach et al., 1987). No caso das crianças socialmente habilidosas, há indícios de que elas de fato discriminam os ambientes do lar e da escola, sendo mais contidas e cooperativas no contexto escolar.

Tabela 5

Resultados das Comparações de Gênero no Grupo IPC (Teste U de Mann-Whitney)

\begin{tabular}{|c|c|c|c|c|}
\hline \multirow[t]{2}{*}{ Variáveis } & \multicolumn{2}{|l|}{ Prof IPC } & \multicolumn{2}{|l|}{ Mãe IPC } \\
\hline & Direção da diferença & $\mathrm{p}$ & Direção da diferença & $\mathrm{p}$ \\
\hline \multicolumn{5}{|l|}{ Habilidades sociais } \\
\hline Procura sua atenção & $\mathrm{M}>\mathrm{F}$ & 0,046 & & \\
\hline Toma iniciativas & & & $\mathrm{F}>\mathrm{M}$ & 0,011 \\
\hline Expressa opiniões & & & $\mathrm{F}>\mathrm{M}$ & 0,018 \\
\hline \multicolumn{5}{|l|}{ Problemas de comportamento } \\
\hline Impaciente, irrequieto & $\mathrm{M}>\mathrm{F}$ & 0,001 & & \\
\hline Destrói objetos & $\mathrm{M}>\mathrm{F}$ & 0,038 & & \\
\hline Briga freqüentemente & $\mathrm{M}>\mathrm{F}$ & 0,030 & & \\
\hline Muitas vezes é desobediente & $\mathrm{M}>\mathrm{F}$ & 0,001 & & \\
\hline Maltrata outras crianças & $\mathrm{M}>\mathrm{F}$ & 0,021 & & \\
\hline Mata ou "enforca" aula & $\mathrm{M}>\mathrm{F}$ & 0,003 & & \\
\hline Recusa-se a entrar na escola & & & $\mathrm{F}>\mathrm{M}$ & 0,041 \\
\hline Tende a ser fechado - solitário & & & $\mathrm{F}>\mathrm{M}$ & 0,011 \\
\hline Fica facilmente preocupado(a) & & & $\mathrm{F}>\mathrm{M}$ & 0,022 \\
\hline
\end{tabular}

Nota. Não foram encontradas diferenças de gênero no grupo ICSA. 
No caso das crianças com problemas de comportamento, assim consideradas tanto pelas professoras como pelas mães, a especificidade situacional pode ser inferida através de outros indícios: as crianças IPC parecem ter, na escola, dificuldade para enfrentar situações interpessoais, mostrando, nesse contexto, menos habilidades para expressar sentimentos, direitos e desejos e, por outro lado, elas brigam mais e maltratam outras crianças, sendo menos queridas pelos colegas. Esse perfil comportamental está coerente com a previsão de que crianças com problemas de comportamento teriam dificuldades para lidar com os desafios interpessoais do ambiente escolar, mais complexo e exigente que o ambiente de suas casas. Como a criança também tem dificuldades em controlar a expressão das emoções negativas geradas nesse cenário, ela tende a externalizar essas emoções. Como conseqüência, seus problemas intensificam-se na escola, o que explica a avaliação aparentemente mais severa da professora em relação à mãe.

$\mathrm{Na}$ perspectiva de especificidade situacional, a maior complexidade do contexto escolar é uma das possíveis explicações para o julgamento mais favorável dos comportamentos problema feito pelas mães, se comparadas às professoras, no grupo IPC. Uma segunda explicação pode ser encontrada na visão da escola como fonte de stress cotidiano (Elkind, 2004). Como as crianças pequenas com problemas de comportamento são mais vulneráveis ao stress escolar (Rende, 1994), mais expostas à rejeição dos companheiros (Hinshaw, 1992) e alvo preferencial de vitimização por parte dos colegas (Kochenderfer \& Ladd, 1996), pode-se supor maior exposição das crianças do grupo IPC a contingências aversivas na escola, o que viria a agravar suas dificuldades.

Assim, o pressuposto de que crianças com problemas de comportamento apresentam comportamentos problemáticos indiscriminadamente, tanto em casa como na escola, explicaria apenas parcialmente os resultados relativos ao grupo IPC já que a comparação entre avaliações de mães e professoras sugere que essas crianças exibem menos comportamentos problemáticos em casa.

De acordo com a hipótese de especificidade situacional, o ambiente escolar, ao oferecer mais oportunidades de interação, também expõe mais a criança a situações de conflito. Ainda que as crianças IPC tenham um repertório de habilidades sociais, identificadas pelas mães no lar, este acaba sendo insuficiente no contexto escolar. Outra hipótese é a de que as mães e as professoras discriminam e conseqüenciam diferentemente os comportamentos socialmente habilidosos das crianças, sendo possível, neste caso, que as professoras o façam menos freqüentemente do que as mães.

Os resultados apontam certa coerência em dois aspectos: por um lado, as crianças mais competentes na escola (segundo o julgamento das professoras) são as que conseguem discriminar melhor os dois contextos; pode-se supor que elas se comportam conforme o ambiente em relação às demandas e ao grau de permissividade ou exigência de adesão a normas sociais. Por outro lado, as crianças com problemas são aquelas que mostram dificuldade de auto-regulação, tanto em casa como na escola e desorganizam-se frente às demandas do ambiente escolar. Pode-se estabelecer uma analogia entre esses resultados e os de estudos sobre regulação das emoções em pré-escolares. Esses estudos mostram que crianças de $3-4$ anos controlam a expressão de emoções negativas em situações sociais não familiares; todavia, essa capacidade está prejudicada nas crianças que são indicadas tanto pelas mães, como pelas professoras, como tendo problemas de comportamento (Cole et al., 1994; LaFreniere \& Dumas, 1996).

Diferenças de gênero foram encontradas apenas no Grupo IPC. Essas diferenças, no geral, foram concordes com a literatura, que refere mais comportamentos externalizantes nos meninos e maior competência social nas meninas (Coolahan et al., 2000; Keane \& Calkins, 2004; Kumpulainen et al., 1999; LaFreniere \& Dumas, 1996; Satake et al., 2003). Contudo, mães e professoras apresentaram padrões diversos de avaliação nas comparações de gênero. As mães de crianças IPC atribuem escores mais altos às meninas em medidas de competência social e internalização. Do seu ponto de vista, as meninas tomariam mais iniciativas e expressariam mais opiniões, como também tenderiam a ser mais fechadas / solitárias e preocupadas. Já as professoras vêem os meninos IPC com mais problemas externalizantes e buscando mais sua atenção.

O comportamento de procurar a atenção é um instigador de interação, e nesse sentido, é considerado como socialmente habilidoso (Bolsoni-Silva, 2000). No entanto, quando em frequência exagerada, ou inapropriado ao contexto, passa a ser considerado como indicativo de problema de comportamento. A busca pela atenção da professora, atribuída em maior grau aos meninos no grupo IPC, pode ser expressa também através de comportamentos externalizantes. Estes comportamentos podem ocorrer, pelo menos em parte, para obter a atenção do adulto. A criança pode procurar a atenção do adulto de maneira "indesejada" por diversos motivos; uma hipótese plausível a ser levantada refere-se ao déficit de competência social, isto é, a criança possuiria dificuldades em obter atenção de forma socialmente habilidosa, ou então teria pouco repertório para resolver problemas na interação com adultos e/ou com pares, expressando seus sentimentos e suas opiniões de maneira agressiva (comportamento externalizante) ou então isolando-se (comportamento internalizante).

Outras diferenças de gênero encontradas referem-se a comportamentos externalizantes e internalizantes. Culturalmente há maior condescendência para comportamentos agressivos e expressão da raiva por parte dos meninos (Cole et al., 1994). Mediante um tal contexto de socialização, podese supor que os meninos acabam emitindo mais freqüentemente comportamentos externalizantes, os quais, por sua maior visibilidade e interferência com o ambiente, contribuem para que mais meninos sejam identificados como tendo problemas de comportamento na escola.

Por outro lado, espera-se que as meninas sejam mais quietas e comportadas, o que pode contribuir para que elas internalizem seu desconforto diante de dificuldades 
encontradas, o que também é indicativo de problema de comportamento (LaFreniere \& Dumas, 1996), já que problemas internalizantes podem dificultar o desenvolvimento social, à medida que ficarão reduzidas as oportunidades de interação e de modelagem de repertórios imprescindíveis ao desenvolvimento e à aquisição de reforçadores, como amizade e afeto.

Os achados das comparações de gênero mostram mães atentas às manifestações internalizantes de suas filhas e professoras ressaltando manifestações externalizantes dos alunos de sexo masculino. Essa aparente divergência suscita algumas reflexões.

Os resultados desta investigação foram discutidos à luz da hipótese de especificidade situacional, com ênfase nos aspectos contrastantes das propriedades dos contextos familiar e escolar. Dentre as diversas interpretações alternativas a essa visão, cabe lembrar a diferença de condições em que mães e professoras fazem seus julgamentos. Nesse sentido, duas distinções parecem ser proeminentes. A primeira é que as professoras, pela sua convivência diária com muitas crianças ao longo dos anos, dispõem de parâmetros normativos com os quais tendem a comparar cada indivíduo avaliado, mesmo que não façam isso conscientemente; esses parâmetros tendem a ser restritivos, visto que as regras e regulamentos vigentes na escola em geral produzem uma redução na variabilidade do comportamento dos alunos. Nesse cenário, há maior probabilidade de considerar como desviantes aquelas crianças cujo comportamento não se enquadra estritamente no padrão modal esperado. A segunda distinção é que, no contexto familiar, diversamente, a mãe tem uma convivência continuada e próxima com seus filhos - em geral, em pequeno número - o que lhe permite observar nuances que escapam ao professor, como, por exemplo, certas manifestações internalizantes mais sutis.

Tais contrastes nas condições de observação contribuem para uma compreensão mais ampla das diferenças nos julgamentos, foco do presente estudo. A par com a hipótese da especificidade situacional, fatores como ter ou não ter parâmatros de comparação para avaliar o comportamento da criança e diferenças no tempo que cada observador permanece com ela provavelmente estão envolvidos no fenômeno, assim como diferenças entre mães e professores nas concepções sobre o desenvolvimento infantil e nas expectativas a respeito do comportamento da criança avaliada (Elkind, 2004; Gagnon et al., 1992; Satake et al., 2003).

Esta pesquisa contribuiu com novos dados para a antiga discussão sobre discrepância entre informantes, quando se trata de avaliar comportamentos de crianças. O exame das hipóteses explicativas para as diferenças de julgamento entre mães e professores ultrapassa seu escopo, entretanto, seus resultados permitem interpretações passíveis de verificação empírica em novos estudos. Como implicação prática, reafirma-se a importância de contar com diferentes informantes, que convivem com a criança em diferentes contextos.

\section{Referências}

Achenbach, T. M., McConaughy, S. H., \& Howell, C. T. (1987) Child / adolescent behavioral and emotional problems: Implications of cross-informant correlations for situational specificity. Psychological Bulletin, 101, 213-232

Bolsoni-Silva, A. T. (2000). Problemas de comportamento e comportamentos socialmente adequados: Sua relação com as habilidades sociais educativas de pais. Dissertação de Mestrado não-publicada, Curso de Pós-Graduação em Educação Especial, Universidade Federal de São Carlos, SP.

Cole, P. M., Zahn-Waxler, C., \& Smith, K. D. (1994). Expressive control during a disappointment: Variations related to preschoolers' behavior problems. Developmental Psychology, 30, 835-846.

Coolahan, K., Fantuzzo, J., Mendez, J., \& McDermott, P. (2000). Preschool peer interactions and readiness to learn: Relationships between classroom peer play and learning behaviors and conduct. Journal of Educational Psychology, 92, 458-465.

Coplan, R. J., Findlay, L. C., \& Nelson, L. J. (2004). Characteristisc of preschoolers with lower perceived competence. Journal of Abnormal Child Psychology, 32, 399-408.

Coplan, R. J., Gavinski-Molina, M-H, Lagacé-Séguin, D. G., \& Wichmann, C. (2001). When girls versus boys play alone: Nonsocial play and adjustment in kindergarten. Developmental Psychology, 37, 464-474.

Del Prette, Z. A. P., \& Del Prette, A. (2005). Psicologia das habilidades sociais na infância. Petrópolis, RJ: Vozes.

Elkind, D. (2004). Sem tempo para ser criança: A infância estressada (3. ed., M. F. Lopes, Trad.). Porto Alegre, RS: Artmed.

Feitosa, F. B. (2003) Relação família-escola: Como pais e professoras avaliam e reagem ao repertório social de crianças com e sem dificuldades de aprendizagem. Dissertação de Mestrado não-publicada, Curso de Pós-Graduação em Educação Especial, Universidade Federal de São Carlos, SP.

Gagnon, C., Vitaro, F., \& Tremblay, R. E. (1992). Parent-teacher agreement on kindergartners' behavior problems: A research note. Journal of Child Psychology and Psychiatry, 33, 12551261.

Graminha, S. S. V. (1994a). A escala comportamental infantil de Rutter A2: Estudos de adaptação e fidedignidade. Estudos de Psicologia, 11, 34-42.

Graminha, S. S. V. (1994b). Problemas emocionais/ comportamentais em uma amostra de escolares; incidência em função do sexo e idade. Psico, 25, 49-74.

Graminha, S. S. V. (1998). Recursos metodológicos para pesquisas sobre riscos e problemas emocionais e comportamentais na infância. In G. Romanelli \& Z. M. Biasoli-Alves (Eds.), Diálogos metodológicos sobre práticas de pesquisa (pp. 71-86). Ribeirão Preto, SP: Legis Summa.

Hinshaw, S. P. (1992). Externalizing behavior problems and academic underachievement in childhood and adolescence: Causal relationships and underlying mechanisms. Psychological Bulletin, 111, 127-155.

Keane, S. P., \& Calkins, S. D. (2004). Predicting kindergarten peer social status from toddler and preschool problem behavior. Journal of Abnormal Child Psychology, 32, 409-423.

Kochenderfer, B. J. \& Ladd, G. W. (1996). Peer victimization: Manifestations and relations to school adjustment in kindergarten. Journal of School Psychology, 34, 267-283. 
Kumpulainen, K., Rãsãnen, E., Henttonen, I., Moilanen, I., Piha, J., Puura, K., \& Tamminen, T. et al. (1999). Children's behavioural /emotional problems: A comparison of parents' and teachers' reports for elementary school-aged children. European Child \& Adolescent Psychiatry, 8, 41-47.

LaFreniere, P. J., \& Dumas, J. E (1996). Social competence and behavior evaluation in children ages 3 to 6 years: The short form (SCBE-30). Psychological Assessment, 8, 369-377.

Pacheco, J., Alvarenga, P., Reppold, C., Piccinini, C. A., \& Hutz, C. (2005). Estabilidade do comportamento anti-social na transição da infância para a adolescência: Uma perspectiva desenvolvimentista. Psicologia: Reflexão e Crítica, 18, 55-61.

Patterson, G., Reid, J., \& Dishion, T. (2002). Antisocial boys. Comportamento anti-social. Santo André, SP: ESETec.

Rende, R. (1994). The stress of first grade and its relation to behavior problems in school. In J.C. De Fries, R. Plomin \& D.W. Fulker (Eds.), Nature and nurture during middle childhood (pp. 152-164). Oxford, UK: Blackwell.

Rosales-Ruiz, J., \& Baer, D. M. (1997). Behavioral cusps: A developmental and pragmatic concept for behavior analysis. Journal of Applied Behavior Analysis, 30, 533-544.

Ruffallo, S. L., \& Elliott, S. N. (1997). Teachers' and parents' ratings of children's social skills: A closer look at crossinformant agreements through an item analysis protocol. The School Psychology Review, 26, 489-501.

Rutter, M. (1967). A children's behaviour questionnaire for completion by teachers: Preliminary findings. Journal of Child Psychology and Psychiatry, 8, 1-11.
Santos, P. L. dos (2002). Riscos e recursos em crianças com alto e baixo rendimento acadêmico: Um estudo comparativo. Tese de Doutorado não-publicada, Curso de Pós-Graduação em Psicologia, Universidade de São Paulo, Ribeirão Preto, SP.

Satake, H., Yoshida, K., Yamashita, H., Kinukawa, N., \& Takagishi, T. (2003). Agreement between parents and teachers on behavioral/emotional problems in japanese school children using the Child Behavior Checklist. Child Psychatry and Human Development, 34, 111-126.

Szelbracikowski, A., \& Dessen, M. A. (2005). Compreendendo a agressão na perspectiva do desenvolvimento humano. In M. A. Dessen \& A. L. Costa Júnior (Eds.), A Ciência do desenvolvimento humano (pp. 231-248). Porto Alegre, RS: Artmed.

Touliatos, J., \& Lindholm, B. W. (1981). Congruence of parents' and teachers' ratings of children's behavior problems. Journal of Abnormal Child Psychology, 9, 347-354.

Webster-Stratton, C. (1996). Early onset conduct problems: Does gender make a difference? Journal of Consulting \& Clinical Psychology, 64, 540-551.
Recebido: 15/03/2005 $1^{a}$ revisão: $13 / 09 / 2005$

$2^{a}$ revisão: $03 / 02 / 2006$ Aceite final: $23 / 03 / 2006$ 